\title{
QUALITATIVE BENCHMARKING STUDY OF SOFTWARE FOR SWITCH PERFORMANCE EVALUATION
}

\author{
Ángel Bernardo Julca Coscol \\ University César Vallejo, (Peru). \\ E-mail: abjulcaj@ucvvirtual.edu.pe ORCID: https://orcid.org/0000-0002-2609-0214 \\ Ghristian David Tapia Prado \\ University César Vallejo, (Peru). \\ E-mail: ctapiapr87@ucvvirtual.edu.pe ORCID: https://orcid.org/0000-0003-4078-7015 \\ Francisco Manuel Hilario Falcón \\ University César Vallejo, (Peru). \\ E-mail: fhilariof@ucvvirtual.edu.pe ORCID: https:/ / orcid.org/0000-0003-3153-9343
}

Cheyer Marcelino Gorpus Giraldo

University César Vallejo, (Peru).

E-mail: cheyergc@gmail.com ORCID: https:// orcid.org/0000-0002-4024-8065

Recepción: 20/08/2021 Aceptación: 16/11/2021 Publicación: 14/12/2021

\section{Citación sugerida:}

Julca A. B., Tapia, C. D., Hilario, F. M., y Corpus, C. M. (2021). Qualitative benchmarking study of software for switch performance evaluation. 3C Tecnología. Glosas de innovación aplicadas a la pyme, 10(4), 35-49. https://doi. org/10.17993/3ctecno/2021.v10n4e40.35-49 


\section{ABSTRACT}

The objective of the research was to compare network software technologies to evaluate the performance of switches based on year of inception, countries implemented, versions, type of software, operating system, programming language, features, tools, benefits, and cost range of implementation. It was concluded that OpUtils is the licensed software with more experience in the market in the technological platforms based on the evaluation of the performance of the software to manage the switches being one of the national and international companies that had a great apogee for its low cost and its quality service. On the other hand, Open vSwitch is the software that shows a high-level index in terms of software updates that allow blocking errors in the source code and patches in poorly developed configurations and maintain security in the management of ports and interfaces for switches. This is due to the fact that the software is based on open-source code allowing to optimize its processes. Finally, it is possible to maintain high standards for privileged users, stop anomalies in real time and stop the cause of the problem is necessary to use a licensed software such as Cisco Open SDN Controller for its full functionality. Finally, some recommendations for future studies were indicated, such as: (a) to perform a classification research covering more than 6 switch management software to increase the alternatives for the selection of a complete software that meets the needs of the stakeholders, (b) to increase the number of variables with the aim of taking the research to a deeper study to provide the support to technical network administrators in the security of devices (switches).

\section{KEYWORDS}

OpenStack, Open vSwitch, OpenQRM, Cisco Open SDN controller, Ni switch executive, OpUtils. 


\section{INTRODUCTION}

Today, the greatest demand for networking organizations to structure traditional network architectures is for quality services. Therefore, for some time now, software-based networking technology platforms have been developed to evaluate the performance of ICT-enabled tools based on virtualization, enabling communication between devices, and maintaining predictable control between these systems. Also, the virtual switch is the backbone of all data center networks because companies employ tools in order to use software resources and have economical and complete networking solutions (Morillo, 2014; Nicolalde, 2021).

Likewise, hubs or switches can have rules created to avoid collisions or traffic increase through the network channels (Toapanta, 2006; Cujilema, 2011). Similarly, they can work at the same speed as all interconnected ports, facilitating the work of each device (Toapanta, 2006; Cujilema, 2011). However, they can make packet forwarding decisions based on specific addresses providing a higher bandwidth for each computer since their configuration is simple and maintains multiple protocols for data transfer in networks of different segmentation in order to end data congestion in the network (Toapanta, 2006; Cujilema, 2011).

In addition, the switch is a tool that has diverse functionalities to manage networks based on protocols that allow seamless communication between systems (Nicolalde, 2021). Therefore, for the evaluation of software it is necessary to perform stress or performance tests in search of various alternatives that can meet the access, scalability, network flexibility, data processing, security and process automation (Cardona, 2019). Regarding this, the switches are modern equipment and in essence those of CISCO can restrict ports and create security policies this is due to the software of the entity that allows to execute these actions when it detects anomalies within the network (Luna, 2019). In that sense, Valencia (2013) developed a graphical network diagram platform of different wiring systems in telephony headquarters to interact through switches in a LAN network allowing DHCP servers and DNS servers to obtain data from the hosts and display it in real time in the technological network diagram in order to manage 
anomalies or connection problems (Valencia, 2013; Cujilema, 2011).

In this research it is proposed to compare software for the evaluation of the performance of switches using free and licensed software based on indicators of previous studies in order to provide relevant information to entities of interest such as those responsible for handling and managing networks allowing them to make a decision based on characteristics that are more suited to the entity, likewise increases the rate of innovation based on software meeting the essential requirements of a software (security, quality of service, routing users, programmable and easy to manipulate) (Morillo, 2014; Valencia, 2013; Luna, 2019; Nicolalde, 2021).

\section{MATERIALS AND METHODS}

The purpose of this study was to compare free software and licensed software for network switch performance evaluation based on the following indicators: Year of inception, Countries Deployed, Versions, Software Type, Operating System, Programming Language, Features, Tools, Benefits and Implementation Cost Range.

The study was qualitative since it describes and defines software technologies to evaluate the performance of switches based on cross-sectional data mining (Sánchez, Fernández y Díaz, 2021). In this regard, Sanchez, Fernandez and Diaz (2021) mentioned that qualitative research has an important potential before society since it is methodology, processes, procedures of concrete and particular performance when collecting data since being evident that it is a technique of greater depth of search. In addition, the design of the study has been topical, with the objective of reaching the specialists or technical managers who make the decision to opt for optimal and quality systems that meet the requirements for the entity. Several researches were evaluated in Scopus, Dyna, EBSCO, Scielo, Elsevier and the technical data of suppliers of these software's focused on switches (Sánchez, Fernández y Díaz, 2021). 


\section{RESULTS}

After detailing the comparative tables of free software and licensed software for the evaluation of switch performance, the most influential characteristics are compared with the results of previous research in order to obtain a similarity, difference and/or comparison with the present study. Likewise, when carrying out the structure of free software and licensed software, it is possible to identify similarities and/or differences found in the indicators selected in the present study with the results of previous research. Therefore, the comparison of data extracted in the comparative tables is shown, disagreed and/or justified. Likewise, it could be observed in the results, that the OpUtils software shows many years of antiquity in the technological and labor market. In this way, it has approximately 25 years in the dedication and practice to offer solutions to users, network administrators who use software for the management and monitoring of switches, where this result shows the difference in the work of Martinez, Valencia and Osorio (2010) where they justified as a result that the Cacti and Nagios software are those technological platforms that currently predominate the operation of the system in the face of anomalies.

On the other hand, the Open vSwitch software versions prove to be constant developments by performing updates in short periods, with the aim of correcting bugs, errors and bad structure in the source code, to maintain security and information in users, this result shows similarity by Pfaff et al. (2015) where they justified as a result that it is advisable to use the Open vSwitch software given the large-scale increase on the variability in the flow and optimization routes to minimize these problems by reducing changes in the software (Pfaff et al., 2015). In addition, OpUtils software is able to adapt to any operating system (Windows and Linux) since its software distributions are easy to install and monitor, this result shows difference to Melwani's work where he mentioned as a result that virtualization is more efficient since its libraries and dependencies, are helpful in creating Docker containers instead of existing as a complete operating system, only including the binaries, necessary libraries and the software we want to virtualize (Melwani, 2018). 
Table 1. Comparison of open-source software for switch performance evaluation.

\begin{tabular}{|c|c|c|c|}
\hline \multirow{2}{*}{ INDICATORS } & \multicolumn{3}{|c|}{ SOFTWARE } \\
\hline & OpenStack & Open vSwitch & OpenQRM \\
\hline START YEAR & $\begin{array}{l}\text { In } 2010 \text { the software was } \\
\text { released for the first time } \\
\text { (OpenStack, 2020). }\end{array}$ & $\begin{array}{l}\text { The foundation of the } \\
\text { software is in } 2009 \\
\text { (Open vSwitch, 2020). }\end{array}$ & $\begin{array}{l}\text { The founding year of } \\
\text { the software was } 2004 \\
\text { (OpenQRM, 2021). }\end{array}$ \\
\hline $\begin{array}{l}\text { COUNTRIES } \\
\text { IMPLEMENTED }\end{array}$ & $\begin{array}{c}\text { United States } \\
\text { (OpenStack, 2020). }\end{array}$ & $\begin{array}{c}\text { United States } \\
\text { (Open vSwitch, 2020). }\end{array}$ & $\begin{array}{l}\text { Australia, Germany } \\
\text { (Cardona, 2019). }\end{array}$ \\
\hline VERSIONS & $\begin{array}{l}\text { Ussuri, Train, Stein, Rocky, } \\
\text { Queens, Pike, Ocata, } \\
\text { Newton, Mitaka, Liberty, Kilo, } \\
\text { Juno, Icehouse, Havana, } \\
\text { Grizzly, Folsom, Essex, } \\
\text { Diablo, Cactus, Bexar, Austin } \\
\text { (OpenStack, 2020). }\end{array}$ & $\begin{array}{c}\text { v2.15.0, v2.14.2, v2.14.1, } \\
\text { v2.14.0, v2.13.3, v2.13.2, } \\
\text { v2.13.1, v2.13.0, v2.12.3, } \\
\text { v2.12.2, v2.12.1, v2.12.0, } \\
\text { v2.11.7, v2.11.6, v2.11.5, } \\
\text { v2.11.4, v2.11.3, v2.11.2, } \\
\text { v2.11.1, v2.11.0, v2.10.7, } \\
\text { v2.10.6, v2.10.5, v2.10.4, } \\
\text { v2.10.3, v2.10.2, v2.10.1, } \\
\text { v2.10.0, v2.9.9, v2.9.8, } \\
\text { v2.9.7, v2.9.6, v2.9.5, v2.9.4, } \\
\text { v2.9.3, v2.9.2, v2.9.1, v2.9.0, } \\
\text { v2.8.11, v2.8.10, v2.8.9, } \\
\text { v2.8.8, v2.8.7, v2.8.6, v2.8.5, } \\
\text { v2.8.4, v2.8.3, v2.8.2, v2.8.1, } \\
\text { v2.8.0, v2.7.13, v2.7.12, } \\
\text { v2.7.11, v2.7.10, v2.7.9, } \\
\text { v2.7.8, v2.7.7, v2.7.6, v2.7.5, } \\
\text { v2.7.4, v2.7.3, v2.7.2, v2.7.1, } \\
\text { v2.7.0, v2.6.10, v2.6.9, } \\
\text { v2.6.8, v2.6.7, v2.6.6, v2.6.5, } \\
\text { v2.6.4, v2.6.3, v2.6.2, v2.6.1, } \\
\text { v2.6.0, v2.5.12, v2.5.11, } \\
\text { v2.5.10, v2.5.9, v2.5.8, } \\
\text { v2 } 5.7, \text { v2.5.6, v2.5.5, v2.5.4, } \\
\text { v2.5.3, v2.5.2, v2.5.1, v2.5.0, } \\
\text { v2.4.0, v2.3.2, v2.3.1, v2.3.0, } \\
\text { v2.1.2, v2.1.1, v2.1.0, v2.0.0, } \\
\text { v1.11.0, v1.10.0, v1.9.0, } \\
\text { v1.7.0, v1.6.1, v1.5.0, v1.4.2, } \\
\text { v1.4.1, v1.4.0, v1.3.0 } \\
\text { (Open vSwitch, 2020). }\end{array}$ & $\begin{array}{l}\text { v.5.3.40, v.5.3.8, v.5.3.5, } \\
\text { v.5.3.2, v.5.3.1, v.5.0.2, } \\
\text { v.4.7, v.4.6, v.4.5, } \\
\text { v.4.4, v.4.3, v. } 4.2, \text { v.4.1 } \\
\text { (OpenQRM, } 2021 \text { ). }\end{array}$ \\
\hline TYPE OF SOFTWARE & $\begin{array}{l}\text { Free software } \\
\text { (Garcia, 2020). }\end{array}$ & $\begin{array}{c}\text { Free Software } \\
\text { (Open vSwitch, 2020). }\end{array}$ & $\begin{array}{c}\text { Free software } \\
\text { (OpenQRM, 2021). }\end{array}$ \\
\hline
\end{tabular}




\begin{tabular}{|c|c|c|c|}
\hline \multirow{2}{*}{ INDICATORS } & \multicolumn{3}{|c|}{ SOFTWARE } \\
\hline & OpenStack & Open vSwitch & OpenQRM \\
\hline OPERATING SYSTEM & $\begin{array}{c}\text { GNU/Linux } \\
\text { (OpenStack, 2020). }\end{array}$ & $\begin{array}{c}\text { GNU/Linux BSD } \\
\text { (Open vSwitch, 2020). }\end{array}$ & $\begin{array}{c}\text { GNU/ Linux } \\
\text { (Gómez, 2013). }\end{array}$ \\
\hline $\begin{array}{l}\text { PROGRAMMING } \\
\text { LANGUAGE }\end{array}$ & $\begin{array}{c}\text { Python } \\
\text { (Garcia, 2020). }\end{array}$ & $\begin{array}{c}\text { Python } \\
\text { (Melwani, 2018). }\end{array}$ & $\begin{array}{c}\text { C, PHP, JAVA } \\
\text { (OpenQRM, 2021). }\end{array}$ \\
\hline CHARACTERISTICS & $\begin{array}{l}\text { It constitutes a network } \\
\text { infrastructure where it is } \\
\text { possible to manage IP } \\
\text { addresses and generate } \\
\text { virtual networks where there } \\
\text { is compatibility with neutron. } \\
\text { Also, the software has a } \\
\text { firewall implementation in the } \\
\text { network with neutron } \\
\text { (Garcia, 2020). }\end{array}$ & $\begin{array}{l}\text { The database information is } \\
\text { protected in new software } \\
\text { updates. On the other hand, } \\
\text { the control configuration in } \\
\text { the kernel module is called. } \\
\text { In such a way, it manages } \\
\text { the control of data flow } \\
\text { between bridges for virtual } \\
\text { interfaces. It also has a } \\
\text { high level of control for the } \\
\text { software service } \\
\text { (Open vSwitch, 2020). }\end{array}$ & $\begin{array}{l}\text { It contains different } \\
\text { virtualization points for IT } \\
\text { support. Also, the software } \\
\text { automates the configuration } \\
\text { automatically under its } \\
\text { entirety } \\
\text { (Gómez, 2013). }\end{array}$ \\
\hline TOOLS & $\begin{array}{l}\text { NetFlow SPAN, RSPAN, } \\
\text { LACP, y 802.1q } \\
\text { (Garcia, 2020). }\end{array}$ & $\begin{array}{l}\text { The domain configuration is } \\
\text { based on the kernel module } \\
\text { control. Thus, it is managed } \\
\text { in the virtual interfaces of } \\
\text { the switches. Likewise, } \\
\text { the control of the data flow } \\
\text { between bridges } \\
\text { (Melwani, 2018). }\end{array}$ & $\begin{array}{l}\text { Virtual machines such as } \\
\text { Debian GNU/Linux, Ubuntu } \\
\text { Linux, CentOS, SuSE/SLES, } \\
\text { Fedora } 9 \text { are used to use } \\
\text { the tools } \\
\text { (OpenQRM, 2021). }\end{array}$ \\
\hline BENEFITS & $\begin{array}{l}\text { It contains a high level of } \\
\text { data security and reliability. } \\
\text { In addition, it acquires a high } \\
\text { distribution and acceptance } \\
\text { in the IP address. Thus, it is } \\
\text { possible to have virtualization } \\
\text { under IP addresses in } \\
\text { Neutron } \\
\text { (OpenStack, 2020). }\end{array}$ & $\begin{array}{l}\text { The network functionality } \\
\text { is incorporated into the } \\
\text { various access points. In } \\
\text { this way, the OVS software } \\
\text { is constituted in two } \\
\text { configurable flow modes in } \\
\text { OVSDB and OpensFlow. } \\
\text { Also, the software is based } \\
\text { on having a compatibility in } \\
\text { bridges } \\
\text { (Open vSwitch, 2020). }\end{array}$ & $\begin{array}{l}\text { It performs in having variety } \\
\text { of plugins in the software } \\
\text { functionality such as the } \\
\text { basics of a DHCP, TFTP } \\
\text { and Local Server. Also, it } \\
\text { manages virtual resources } \\
\text { in plugin activation where it } \\
\text { is mentioned with Xen and } \\
\text { Storage-Xen } \\
\text { (OpenQRM, 2021). }\end{array}$ \\
\hline
\end{tabular}

Source: own elaboration. 
Table 2. Comparison of licensed software for switch performance evaluation.

\begin{tabular}{|c|c|c|c|}
\hline \multirow[b]{2}{*}{ INDICATORS } & \multicolumn{3}{|c|}{ SOFTWARE } \\
\hline & $\begin{array}{c}\text { Cisco Open SDN Controller } \\
\text { (Cisco Open SDN Controller, } \\
\text { 2014). }\end{array}$ & NI Switch Executive. & OpUtils. \\
\hline START YEAR & $\begin{array}{l}\text { In the foundation year of the } \\
\text { proposed software was } 2014 \\
\text { (Cisco Open SDN Controller, } \\
\text { 2014). }\end{array}$ & $\begin{array}{l}\text { The year the software was } \\
\text { founded was } 2004 \text { (Ni Switch } \\
\text { Executive, 2021). }\end{array}$ & $\begin{array}{l}\text { The founding year of the } \\
\text { proposed software was } \\
1996 \text { (OpUtils, 2020). }\end{array}$ \\
\hline $\begin{array}{l}\text { COUNTRIES } \\
\text { IMPLEMENTED }\end{array}$ & $\begin{array}{c}\text { United States, Canada } \\
\text { (Cisco Open SDN Controller, } \\
\text { 2014). }\end{array}$ & $\begin{array}{l}\text { United States, Spain, and } \\
\text { Latin America (Ni Switch } \\
\text { Executive, 2021). }\end{array}$ & $\begin{array}{l}\text { United States, Japan, Spain, } \\
\text { Germany, China (OpUtils, } \\
\text { 2020). }\end{array}$ \\
\hline VERSIONS & $\begin{array}{c}\text { v.1.2, v.1.2.1, v.1.1, v.1.0 } \\
\text { (Cisco Open SDN Controller, } \\
\text { 2014). }\end{array}$ & $\begin{array}{c}\text { v.3.5, v.3.0, v. } 2.0 \text { (Ni Switch } \\
\text { Executive, } 2021)\end{array}$ & $\begin{array}{l}\text { v.12.3, v.11.0, v.6.0, v.5.0 } \\
\text { (OpUtils, 2020). }\end{array}$ \\
\hline $\begin{array}{l}\text { TYPE OF } \\
\text { SOFTWARE }\end{array}$ & $\begin{array}{c}\text { Licensed Paid Software } \\
\text { (Cisco Open SDN Controller, } \\
\text { 2014). }\end{array}$ & $\begin{array}{l}\text { Licensed Paid Software (Ni } \\
\text { Switch Executive, 2021). }\end{array}$ & $\begin{array}{l}\text { Free Software/ Licensed } \\
\text { Paid Software (OpUtils, } \\
\text { 2020). }\end{array}$ \\
\hline $\begin{array}{l}\text { OPERATING } \\
\text { SYSTEM }\end{array}$ & $\begin{array}{l}\text { Linux (Cisco Open SDN } \\
\text { Controller, 2014). }\end{array}$ & $\begin{array}{l}\text { Windows (Ni Switch } \\
\text { Executive, 2021). }\end{array}$ & $\begin{array}{l}\text { Windows, Linux (OpUtils, } \\
\text { 2020). }\end{array}$ \\
\hline $\begin{array}{l}\text { PROGRAMMING } \\
\text { LANGUAGE }\end{array}$ & $\begin{array}{l}\text { Java (Cisco Open SDN } \\
\text { Controller, 2014). }\end{array}$ & $\begin{array}{c}\text { C\#, VB .NET, C/C++ y } \\
\text { ActiveX, Python (Ni Switch } \\
\text { Executive, 2021). }\end{array}$ & Java (OpUtils, 2020). \\
\hline CHARACTERISTICS & $\begin{array}{l}\text { The software is distributed, } \\
\text { enforced, validated, and } \\
\text { supported by its commercial } \\
\text { distribution. On the other } \\
\text { hand, high availability } \\
\text { and quality in clustering is } \\
\text { maintained. In addition, ease } \\
\text { of service is maintained for } \\
\text { monitoring, metrics collection } \\
\text { and risk management (Cisco } \\
\text { Open SDN Controller, 2014). }\end{array}$ & $\begin{array}{l}\text { The integration of several } \\
\text { modules can be automated. } \\
\text { Likewise, it is identified in } \\
\text { the configuration of the } \\
\text { deployment of switches from } \\
\text { a file or network. Where the } \\
\text { configuration of software } \\
\text { modules and drivers is } \\
\text { guaranteed (Ni Switch } \\
\text { Executive, 2021). }\end{array}$ & $\begin{array}{l}\text { IP addresses are managed. } \\
\text { Ports are also managed. } \\
\text { In this way, the control } \\
\text { of unauthorized devices. } \\
\text { It is managed in the } \\
\text { Configuration Files (OpUtils, } \\
\text { 2020). }\end{array}$ \\
\hline TOOLS & $\begin{array}{l}\text { Allows you to manage Cisco } \\
\text { OpensFlow. Thus, it is } \\
\text { administered in Cisco PCEP. } \\
\text { It also allows to manage } \\
\text { Cisco BGPLS (Cisco Open } \\
\text { SDN Controller, 2014). }\end{array}$ & $\begin{array}{l}\text { LabVIEW, LabVIEW NXG, } \\
\text { LabWindows/CVI (Ni Switch } \\
\text { Executive, 2021). }\end{array}$ & $\begin{array}{c}\text { SNMP Tool, CISCO Tools, } \\
\text { Diagnostic Tools, Network } \\
\text { Monitoring Tools, IP Address } \\
\text { Monitoring Tools, Network } \\
\text { Tools (OpUtils, 2020). }\end{array}$ \\
\hline
\end{tabular}




\begin{tabular}{|c|c|c|c|}
\hline \multirow{2}{*}{ INDICATORS } & \multicolumn{3}{|c|}{ SOFTWARE } \\
\hline & OpenStack & Open vSwitch & OpenQRM \\
\hline BENEFITS & $\begin{array}{l}\text { Automate standards-based } \\
\text { network infrastructure. It } \\
\text { also allows optimizing the } \\
\text { acceleration in information } \\
\text { technology. (Cisco Open } \\
\text { SDN Controller, 2014). }\end{array}$ & $\begin{array}{l}\text { Manage network } \\
\text { performance on the } \\
\text { switch. In this way, it } \\
\text { allows to stimulate the } \\
\text { values of the network } \\
\text { domain. It also enables } \\
\text { logging and reporting of } \\
\text { performance test failures. } \\
\text { It also allows directing } \\
\text { switching operations. Where } \\
\text { calculations and data } \\
\text { manipulation are performed } \\
\text { (Ni Switch Executive, 2021). }\end{array}$ & $\begin{array}{l}\text { Monitor packet losses and } \\
\text { discards of errors that you } \\
\text { have in the network under } \\
\text { critical metrics. In such } \\
\text { a way, it visualizes the } \\
\text { services of the physical } \\
\text { servers. It also allows to } \\
\text { manage the WAN and VolP } \\
\text { network (OpUtils, 2020). }\end{array}$ \\
\hline $\begin{array}{l}\text { IMPLEMENTATION } \\
\text { COST RANGE }\end{array}$ & $\begin{array}{c}\text { Standard } \\
\$ 795.00-\$ 928.00 \\
\text { Professional } \\
\$ 1,031.00-\$ 5,995.00 \\
\text { Enterprise } \\
\$ 6,216.0-\$ 300,000.00 \text { (Cisco } \\
\text { Open SDN Controller, 2014). }\end{array}$ & $\begin{array}{c}\$ 1,690.00 \\
\text { (Ni Switch Executive, 2021). }\end{array}$ & $\begin{array}{r}\$ 195.00 \text { - \$2,995.00 } \\
\text { (Martínez et al., 2010). }\end{array}$ \\
\hline
\end{tabular}

Source: own elaboration.

The OpenStack software demonstrates better technological qualities based on the quality of service control for integrated storage management, allowing the automation of modules, port management, IP addresses, configuration files and drivers of the application software, where this result is similar to the study of Garcia when mentioning that the OpenStack software has future possibilities to adapt to new technological changes, achieve constant updates and the possibility of having a distributed IaaS private cloud (Nicolalde, 2021).

On the other hand, OpUtils software then there are different types of tools that have facilitated the user to have network security. Similarly, the OpUtils software is very feasible with its management processes, such as: diagnostics, network monitoring, IP address monitoring, port management and anomaly 
detection, this result is different from Ramos when describing the Open vSwitch software maintains a controlled configuration and an organized database scheme given by its tools: Ovs- vsctl, Ovs-ofctl and Ovs-testcontroller which are utilities and drivers to administer, configure, query and manage the ports of the switch interfaces. Next, the Open vSwtich software incorporates functionalities within the network based on the processes of the switches by the use of configurable flows, software compatibility and its high margin in its processing in sending software packages to hardware, this study is different from that of Martinez, Valencia and Osorio (2010) when performing an evaluation of analysis and management tools (Cacti and Nagios) for its ability to identify and analyze functionalities in the ports of the switches in the network, easy configuration, process optimization and meet the needs of the case based on the performance of the default software (Martínez et al., 2010).

Finally, the Open vSwitch open-source software shows to be a good function for medium-sized organizations for its ease of use, modification of the software itself and user domain, in addition to maintaining a phase of installation and management of resources mitigating problems such as ports and interfaces of the switches on the network, in this regard coincides with the work of Martinez, Valencia and Osorio (2010) mentioned that it is necessary to have monitoring tools for network devices to solve problems based on ICT resources, which is why they mention having licensed software to maintain high standards for users on the network and not being able to limit solutions to anomalies with a margin from \$195 to \$2,995 (Martínez et al., 2010).

\section{CONCLUSIONS}

The conclusions of the research were as follows: OpUtils is the most experienced licensed software in the market in technology platforms based on the evaluation of the performance of the software to manage switches being one of the national and international companies that had a great heyday for its low cost and quality service (OpUtils, 2020). On the other hand, Open vSwitch is the software that shows a high level of software updates that allow blocking errors in the source code and patches in poorly developed 
configurations and maintain security in the management of ports and interfaces for switches. This is due to the fact that the software is based on open-source code allowing to optimize its processes (Open vSwitch, 2020). Thus, OpUtils software is the best option because it can be adapted to the operating systems most commonly used in technological entities (Windows and Linux); since its distributions and dependencies are the easiest way to install and manipulate the software based on the management, administration and monitoring of the switches in the network (OpUtils, 2020).

Next, the OpenStack software shows a great difference compared to the switch software, since it shows technological peculiarities focused on the quality of service control, allowing to manage, automate and optimize port modules and controllers of the application software, adapting to the existing technological changes (OpenStack, 2020; Garcia, 2020). On the other hand, OpUtils is the software that has the most popular and applied options for medium-sized organizations because it is able to facilitate the user in keeping the network secure in the switches given in its management processes (diagnostics, network monitoring, port management and anomaly detection (OpUtils, 2020).

In addition, Open vSwtich software proved to be a good choice for SMEs because it incorporates security functionalities on switch ports in the network due to its simple configurable flow, software compatibility and high processing margin in sending software packages to hardware (OpenStack, 2020). In addition, Open vSwitch software is the only open-source brand suitable for small and medium-sized organizations due to its ease of use, proprietary software modification and user control. In addition, it maintains full resource management by mitigating problems on ports and switch interfaces in the network (Open vSwitch, 2020). Finally, it can maintain high standards for privileged users, real-time anomaly detention and stop the cause of the problem is necessary to employ a licensed software such as Cisco Open SDN Controller for its full functionalities (Cisco Open SDN Controller, 2014). 


\section{RECOMMENDATIONS}

The recommendations of this research are the following: this qualitative study can be continued in a quantitative way by assigning variables, numerical and statistical data to measure the selected and mentioned indicators. To carry out a classification study is a good option to obtain the evaluation software in the performance of switches and which one is the most suitable for specific sectors and network administrators. To develop the research work using the convergent mixed method to obtain qualitative and quantitative data and to compare the information in search of similarity and/or difference. It is recommended to conduct longitudinal studies to analyze and detail technological changes in the evaluation of switch software performance. Perform a classification research covering more than 6 switch management software to increase the alternatives for the selection of a complete software that meets the needs of the stakeholders. Finally increase the number of variables with the objective of taking the research to a more in-depth study to provide support to technical network administrators in the security of ports on switches.

\section{REFERENCES}

Gardona, J. (2019). Design of a theoretical and practical guide on software-defined networks (SDN) for the Santiago de Cali University (Thesis). https://repository.usc.edu.co/handle/20.500.12421/4158c

Gisco Open SDN Gontroller. (2014). Cisco Open SDN Controller. Cisco. https://www.cisco.com/c/en/ us/support/cloud-systems-management/open-sdn-controller/series.html?dtid=osscdc000283

Gujilema, D. (2011). Proposed Solution to Insecure Access to Resources in Corporate LAN Networks Using Free Software Network Access Control Applications (Thesis). Chimborazo Polytechnic Higher School, 114 pp. http://dspace.espoch.edu.ec/bitstream/123456789/983/1/38T00274\%20UDGTFIYE.pdf 
Garcia, D. (2020). OpenStack: An Infrastructure as a Service alternative for higher education institutions. Information Technology Research fournal: RITI, 8(15). 1-17. https://dialnet.unirioja.es/ servlet/articulo? codigo $=7237680$

Gómez, G. (2013). Processing of large volumes of data in CLOUD COMPUTING environments using HADOOP MAPREDUCE (Thesis). University of Almería. http://repositorio.ual.es/bitstream/ handle/10835/2189/TRABAJOCarlos\%20Gomez\%20Martinez.pdf?sequence=1

Luna, A. (2019). Switch port security. Networks and telecommunications. http://ri.utn.edu.mx/handle/ 123456 789/114? show $=$ full\&locale-attribute $=$ en

Martínez, F., Valencia, J., \& Osorio, O. (2010). Using Open Source Tools to Manage Network Devices: An Automotive Security Components Company Case. In XIV International Congress of the Academy of Administrative Sciences A.C. (ACACIA). 1-30. http://acacia.org.mx/busqueda/pdf/ C11P14C.pdf

Melwani, K. (2018). Simulation of a Commercial switch on Open vSwitch. University of the lagoon. https:// riull.ull.es/xmlui/bitstream/handle/915/8630/Simulacion\%20de\%20un\%20switch\%20 comercial $\% 20$ sobre $\% 200$ pen $\% 20$ vSwitch $\% 20$.pdf? sequence $=1$

Morillo, D. (2014). Implementation of a prototype of a software-defined network (SDN) using a softwarebased solution (Thesis). National Polytechnic School, 196 pp. https://bibdigital.epn.edu.ec/ bitstream/15000/7360/1/CD-5509.pdf

NI Switch Executive. (2021). Small size, big performance. https://www.ni.com/

Nicolalde, W. (2021). Design of an intrusion detection system (IDS), based on neural networks for a softwaredefined network (SDN) in the faculty of engineering in applied sciences (fica) of the northern technical university (Thesis). Technical University of the North, 199 pp. http://repositorio.utn.edu.ec/ bitstream/123456789/10907/2/04\%20RED\%20254\%20TRABAJO\%20GRADO.pdf 
Open vSwitch. (2020). Production quality, multilayer open virtual switch. http:/ /www.openvswitch.org/

OpenQRM. (2021). Professional open source data center and cloud management. https://openqrm-enterprise. $\mathrm{com} /$

OpenStack. (2020). The most widely deployed open source cloud software in the world. https://www.openstack. org/

OpUtils. (2020). OpUtils - Product overview. ManageEngine. https://www.manageengine.com/products/ oputils/oputils.html

Pfaff, B., Pettit, J., Koponen, T., Jackson, E., Zhou, A., Rajahalme, J., Gross, J., Wang, A., Stringer, J., \& Shelar, P. (2015). The Design and Implementation of Open vSwitch. In 12th USENIX Symposium on Networked Systems Design and Implementation (NSDI '15). 1-15. https://www. usenix.org/system/files/conference/nsdi15/nsdi15-paper-pfaff.pdf

Sánchez, M., Fernández, M., \& Díaz, J. (2021). Information gathering techniques and instruments: analysis and processing carried out by the qualitative researcher. UISRAEL Scientific fournal, 8(1), 107-121. https://doi.org/10.35290/rcui.v8n1.2021.400

Toapanta, B. (2006). Design and implementation of a basic Linux-based layer 3 switch prototype. Thesis (Title in Information and Computing Systems (ISIS)), Quito: Escuela Politécnica Nacional. 193 pp. https://bibdigital.epn.edu.ec/bitstream/15000/146/1/CD-0164.pdf

Valencia, G. (2013). Network map, contingency plan update, installed software control, maintain tools from previous practices, support, documentation - telefonica de Pereira in 2012 (Thesis). Catholic University of Pereira. 40 pp. https://repositorio.ucp.edu.co/bitstream/10785/1365/1/CRISTIAN\%20CAMILO\%20 VALENGIA\%20CORREA.pdf 
